\title{
RESPON MASYARAKAT TERHADAP REKLAMASI LAHAN BEKAS TAMBANG SEMEN SEBAGAI EKOWISATA DI DAERAH SALE KABUPATEN REMBANG
}

\author{
Sudarti ${ }^{1}$, Siti Hindun Hindiyati ${ }^{2}$ \\ ${ }^{\text {l} P e n d i d i k a n ~ F i s i k a ~ U n i v e r s i t a s ~ J e m b e r, ~ J e m b e r, ~ I n d o n e s i a, ~ E m a i l: s u d a r t i . f k i p @ ~ @ n e j . a c . i d ~}$ \\ ${ }^{2}$ Pendidikan Fisika Universitas Jember, Jember, Indonesia, Email:hindunhindya177@ gmail.com
} ABSTRAK

Pertambangan merupakan salah satu aktifitas yang memiliki dampak buruk bagi lingkungan dan memiliki dampak positif bagi masyarakat sekitar. Dengan adanya pertambangan, masyarakat dapat menyambung hidup dengan bekerja sebagai bagian dari perusahaan, dan disisi lain pertambangan juga memiliki dampak negative yang mana dapat menghilangkan keseimbangan ekosistem dengan adanya pengerukan lahan secara besarbesaran. Teori yang digunakan adalah teori respon, yang merupakan tanggapan, reaksi dan jawaban. Respon yang diambil adalah dari masyarakat sekitar di daerah Sale Kabupaten Rembang, dan respon perusahaan. Respon perusahaan ada beberapa yang berbanding terbalik dengan respon masyarakat mengenai adanya reklamasi. Harapan masyarakat dengan adanya pertambangan, pada akhirnya bila sudah tidak digunakan harus dilakukan pengembalian lahan atau reklamasi. Metode penelitian yang digunakan adalah deskiriptif kuantitatif dengan penarikan sampel menggunakan responden, yang mana 60 jiwa masyarakat Sale digunakan sebagai responden penelitian. Teknik dan pengumpulan data yang digunakan adalah observasi dan wawancara. Hasil penelitian menunjukkan bahwa seluruh masyarakat bersedia mengelola lahan bekas tambang yang sudah tidak digunakan akan diserahkan kepada masyarakat dan dilakukan reklamasi skala mikro sebagai ekowisata. Dengan catatan, setidaknya perusahaan harus memberikan sedikit biaya operasional dan ganti rugi lahan masyarakat.

Kata Kunci: Respon; Ekowisata; Lahan Bekas Tambang; Reklamasi; Inovasi

\section{COMMUNITY RESPONSE TO LAND RECLAMATION OF EX-CEMENT MINING AS ECOTURISM IN THE SALE AREA, REMBANG REGENCY}

\begin{abstract}
Mining is one of the activities that has a bad impact on the environment and has a positive impact on the surrounding community. With mining, the community can make a living by working as part of the company, and on the other hand mining also has a negative impact which can remove the balance of the ecosystem through massive land dredging. The theory used is the response theory, which is the response, reaction and answer. The responses taken were from the surrounding community in the Sale area, Rembang Regency, and the response from the company. There are several company responses that are inversely proportional to the response of the community regarding the existence of reclamation. The hope of the community is that with mining, in the end when it is not used, land returns or reclamation must be carried out. The research method used is descriptive quantitative with
\end{abstract}


respond using 60 people Sale regency, in which the entire population is used as research respondents. Techniques and data collection used were observation and interviews. The results showed that the whole community was willing if the ex-mining land that was not used would be handed over to the community and micro-scale reclamation was carried out as ecotourism. With a note, at least the company must provide a small amount of operational costs and compensation for community land.

Copyright @2021. UHN IGB Sugriwa Denpasar. All Right Reserved pekerja yang diambil hanya beberapa sebagai pekerja berat dan sisanya diambil

\section{PENDAHULUAN}

Kecamatan Sale merupakan salah satu kecamatan yang di Kabupaten Rembang, Jawa Tengah. Kecamatan Sale ini terletak di perbatasan antara Jawa Tengah dengan Jawa Timur, yang mana pada sebelah timur berbatasan dengan Kecamatan Jatirogo, Kabupaten Tuban Jawa Timur. Kecamatan Sale ini terkenal akan sumber daya alam yang sering disebut dengan hutan semen. Banyaknya pertambangan kapur putih yang dijadikan sebagai bahan baku semen membuat banyak wisatawan yang ingin berkunjung dan sekedar melihat hutan semen yang ada di Sale. Menurut informasi yang didapat, di Kecmatan Sale Kabupaten Rembang setidaknya memiliki 33 PT dan $1 \mathrm{CV}$. Semua proses pertambangan ini masih berproses hingga saat ini. Sebagian besar masyarakat Sale bermata pencaharian sebagai petani dan tidak sedikit pula ikut andil dalam beberapa perusahaan yang berdiri di Kecamatan Sale.

Menurut Afifah, Harianto, 2014 menyebutkan pada beberapa daerah, banyak lahan yang sebelumnya dijadikan sebagai lahan pertanian namun dialih fungsikan sebagai tambang semen. Adanya salah satu dampak negative dari industry tambang bahan baku semen terhadap masyarakat desa dalam aspek progress dan regress. Aspek lingkungan sendiri yang disebutkan yaitu kelangkaan sumber daya alam dan akan menimbulkan terjadinya kerusakan lingkungan. Lalu, aka nada dampak negative dari aspek social diantaranya adalah marginialisasi pekerjaan dan pemudaran modal social. Sedangkan dalam ekonomi, banyak dari luar daerah. Sedangkan pada dampak lingkungan dapat dirasakan oleh masyarakat sekitar yaitu dengan adanya peningkatan suhu, dan juga banyak debu yang mengganggu pernapasan. Dengan adanya peristiwa pasca tambang, lahan setelah selesai digali tidak dikembalikan asalnya akan merusak keseimbangan ekosistem.

Untuk mengatasi hal ini dapat dilakukan dengan cara reklamasi atau pengembalian lahan dengan menyeimbangkan ekosistem seperti semula. Menurut Iskandar,et all.2012 menyebutkan bahwa istilah reklamasi memiliki tujuan untuk membenahi unsur hara, revegetasi lahan dan menghadapi seluruh permasalahan seperti lereng tidak stabil, sedimentasi, tanah memiliki unsur toxic tinggi terhadap tanaman dan lainlain. Adanya reklamasi ini diharapkan dapat menggugah mahasiswa fisika yang menempuh mata kuliah fisika lingkungan dengan menerapkan teori kedalam aplikasian masyarakat. Output yang akan didapatkan oleh masyarakat yaitu dapat membuka wisata.

Wisata yang dapat diterapkan pada lahan bekas tambang batu kapur sendiri ada macam yang umum yaitu geowisata dengan ekowisata. Menurut Indrayati, Setyaningsih, 2017 menyebutkan bahwa geowisata merupakan kegiatan wisata minat khusu mengenai bagimana kenampakan keadaan geologis terhadap suatu daerah tanpa adanya perubahan dalam daerah tersebut. Geowisata dapat disebut sebagai tempat yang menopang atau mingkatkan karakter geografis tempat yang dikunjungi, lingkungan, budaya dan estetika. Jadi, pada kegiatan 
geowisata ini lahan bekas tambang dibiarkan apa adanya tanpa ditanami pohon. Sedangkan pada artikel ini gua meningkatkan penghijauan di Indonesia kita akan menggunakan landasan ekowisata sebagai hasil reklamasi. Ekowisata dapat diartikan sebagai perjalanan wisata ke wilayah-wilayah alami dalam rangka mengkonversi atau menyelamatkan lingkungan dan memberikan kehidupan bagi penduduk lokal (Utami,2017).

Gagasan ini ditulis bertujuan untuk mengetahui respon masyarakat tentang adanya pertambangan secara berlebihan di daerah mereka, serta bagaimana tanggapan masyarakat tentang adanya reklamasi secara mandiri berbasis ekowisata sebagai upaya pengembalian keseimbangan ekosistem. Selain itu, gagasan ini ditulis bertujuan untuk meningkatkan kesadaran masyarakat akan pentingnya menjaga ekosistem.

\section{Metode}

Metode penelitian yang digunakan penulis pada penekitian ini merupakan kuantitatif dan deskriptif, yaitu metode pencarian fakta dengan interpretasi yang tepat

\subsection{Observasi Lapangan}

Penelitian ini dilaksanakan pada OktoberNovember 2020 selama 2 bulan di perusahaan tambang CV. AMP, PT. BIO Kecamatan Sale Kabupaten Rembang. Dengan melaksanakan survey lahan yang dilakukan pada tanggal 23 November 2020 dengan sampel penelitian yakni lahan bekas tambang dekat CV AMP dengan lebar lahan sekitar 2 ha.

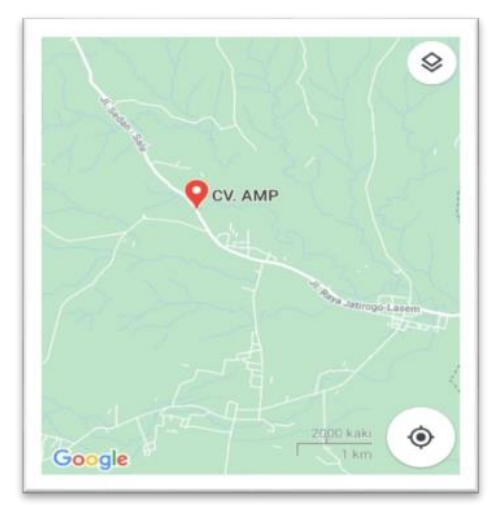

Gambar 1.1 peta lokasi lapangan

\subsection{Populasi dan Sampel}

\subsubsection{Populasi}

Populasi merupakan wilayah yang terdiri dari objek ataupun subjek yang memiliki kualtias dan karakteristik tertentu yang ditetapkan peneliti untuk dipelajari lalu ditarik kesimpulan.

\subsubsection{Sampel}

Sampel merupakan sebagian dari jumlah dan karakteristik yang dimiliki populasi tersebut. Teknik penarikan sampel yang dilakukan dalam penelitian kali ini adalah melibatkan 60 responden yang merupakan masyarakat Sale Kabupaten Rembang.

\subsection{Teknik Pengumpulan Data 2.3.1 Angket (Kuisioner)}

Metode kuisioner ini dapat dilakukan dengan mengajukan sejumlah pertanyaan kepada responden.

\subsubsection{Dokumentasi}

Dokumentasi dapat dilakukan dengan pengambilan foto menggunakan alat seadanya misalnya telepon genggam untuk mendukung orisinalitas dari informasi dan data yang didapatkan.

\subsection{Jenis Data dan Sumber Data}

Jenis data dan sumber data yang dibutuhkan dalam penelitian ini diantaranya adalah:

\subsubsection{Data Primer}

Data primer merupakan data yang diperoleh secara langsung di lapangan dan respon dari masyarakat

\subsubsection{Data Sekunder}

Data sekunder merupakan data yang didapat dari berbagai sumber seperti kajian pustaka, artikel, blog, instansi yang berkaitan dengan topik penelitian.

\subsection{Analisis Data}

Proses analisis data dapat dilakukan dengan bantuan table deskriptif, table yang dapat menjelaskan hasil wawancara dari responden masyarakat sekitar Kecamatan Sale Kabupaten Rembang.

\section{HASIL DAN PEMBAHASAN}

\subsection{Reklamasi}

Reklamasi merupakan salah satu langkah yang dapat dilakukan untuk mengembalikan lahan pasca tambang. Lahan pasca tambang biasanya memiliki 
komposisi toxic berlebihan bagi tanaman yang akibatnya mempengaruhi tingkat kesuburan bagi tanah dan menghambat pertumbuhan tanaman. Pada beberapa daerah yang sudah menjadi pasca tambang, tidak semua direklamasi karena seperti kita tahu hal tersebut memerlukan biaya yang sangat besar dan tidak mudah. Fungsi dari reklamasi sendiri merupakan mengembalikan keseimbangan ekosistem yang sudah hilang selama pertambangan dilakukan. Pengembalian ekosistem di lahan bekas tambang dapat dilakukan dengan menata kembali lahan dan menanami dengan tanaman yang sesuai.

\subsection{Penentuan Tanaman untuk Lahan}

\section{Bekas Tambang}

Menurut penelitian Pudjiharta et al 2007, menjelaskan bahwa dari waktu pengamatan yang relatif pendek (dua bulan) terlihat bahwa jenis pohon yang mampu beradaptasi hidup lebih baik adalah jenis Pinus merkusii Jungh et de Vriese dan Acacia mangium Willd yang mempunyai pertumbuhan relatif lebih baik dari jenis lainnya. Menurut Zulkifli,2013 dan Baskorowati, 2014 menyebutkan bahwa revegetasi menjadi kegiatan yang wajib dilakukan pada lahan bekas penambangan, namun seringkali upaya revegetasi menghadapi kendala yang cukup berat. Pada lahan bekas tambang membutuhkan jenis tanaman yang mampu beradaptasi pada daerah kering dan miskin unsur hara. Sengon (Paraserianthes falcataria (L.) Nielsen) merupakan salah satu tanaman yang tidak membutuhkan persyaratan tumbuh tinggi karena mampu hidup pada tanah miskin hara. Sengon juga merupakan jenis tanaman komersil yang menguntungkan dan termasuk jenis cepat tumbuh (fast growing species) sehingga cocok untuk revegetasi lahan bekas tambang.

\subsection{Hasil Wawancara dengan Salah Satu Pihak Perusahaan}

Hasil wawancara dengan pihak perusahaan, menjelaskan bahwa perusahaan berdiri pertama kali pada tahun 1997 yang memiliki nama CV AMP. setidaknya ada33 PT dan $1 \mathrm{CV}$ yang ada di Sale Kabupaten Rembang. PT terbesar yang ada di sana adalah PT SAF dan PT Bio. Pemiliki dari perusahaan CV AMP merupakan warga local daerah Sale Kabupaten Rembang. Menurut pihak perusahaan menyatakan bahwa masyarakat tidak pernah menolak atau tidak ada penolakan tentang berdirinya tambang karena sudah menemukan mufakat. Salah satunya adalah dengan syarat masyarakat harus dilibatkan penuh dalam operasi tambang, produksi menggunakan manual atau breaker yang ramah lingkungan (tidak menggunakan peledak). Dan memenuhi surat amdal tentang pembatasan kedalaman pertanbangan. Dengan adanya pertambangan ini, perekonomian masyarakat Sale meningkat secara signifikan dengan semua pekerja yang dilibatkan adalah warga local. "yaa daripada tidak ada kerjaan" tutur Pak Janeng selaku salah satu satpam yang menjawab pertanyaan. Membahas tentang reklamasi, pihak perusahaan belum bisa menjawab dengan mengatakan "yaa saya tidak tahu uaya mbak kan ini juga masih beroperasi"

\subsection{Hasil Observasi Lahan}

Hasil observasi lahan dapat ditunjukkan dengan pengambilan gambar menggunakan telepon genggam di bawah ini.

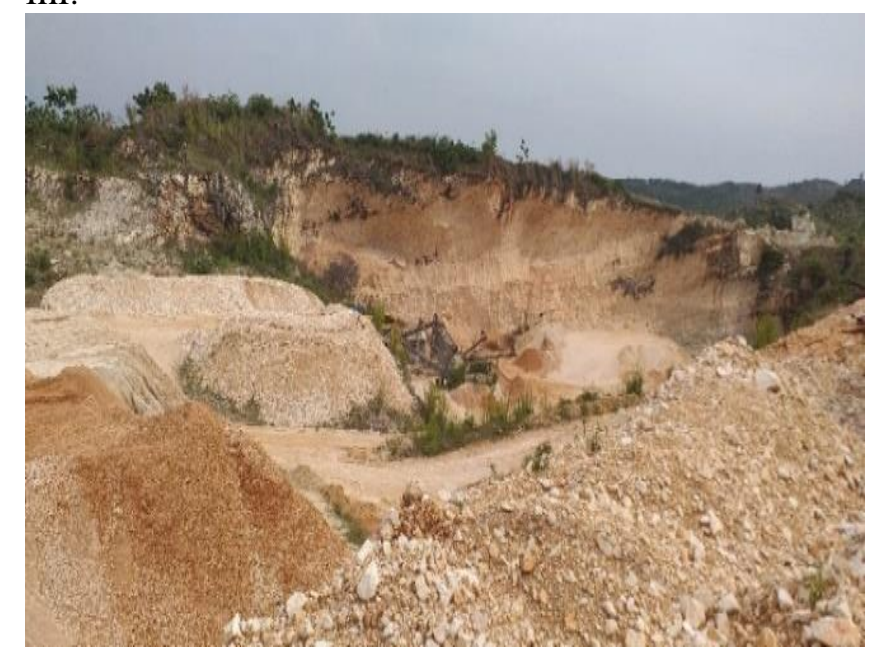

Gambar 1. Kondisi lahan 
Dari gambar di atas, dapat disajikan data sebgai berikut:

Tabel 1. Keadaan Lahan Penggalian

\begin{tabular}{cll}
\hline NO. & Masalah & Kondisi \\
\hline $\mathbf{1 .}$ & Tanah & Kering \\
\hline $\mathbf{2 .}$ & Kedalaman & 6 meter \\
\hline $\mathbf{3 .}$ & Tinggi & 6 meter \\
& Tebing & \\
\hline $\mathbf{4 .}$ & Komposisi & -Batu 30\% \\
& & -Tanah \\
& & $50 \%$ Merah \\
& & -Pasir20\% \\
\hline $\mathbf{5 .}$ & Kesuburan & Tidak subur \\
\hline & Sumber: Data Primer (2020)
\end{tabular}

Keadaan lahan yang ada di daerah pertambangan cukup memprihatinkan, karena banyaknya debu yang sudah banyak sebelum memasuki kawasan pertambangan, hawa panas meski berawan juga menambah kesan dekat pada daerah pertambangan, saat itu suhunya mencapai 36 derajat dan keadaan sedang berawan. Pemerintah setempat juga mewajibkan memakai masker saat memasuki daerah pertambangan radius $5 \mathrm{~km}$. lahan yang didominasi dengan tanah merah serta bebatuan ini membuat ketika musim hujan akan sangat bermasalah. Terlihat ada beberapa tumbuhan yang masih rimbun salah satunya adalah pohon jati karena memang masih ada beberapa lahan yang beluk dilakukan pertambangan. Sedangkan pada lahan yang sedang ditambang, ada tanaman baru yang terlihat namun tumbuh tidak subur (layu) meski terlihat dibawah sudah agak basah (kondisi sudah disiram). Hal ini menjelaskan bahwa tanah yang ada di sekitar pertambangan memiliki kandungan yang kurang baik bagi tumbuhan dan juga memiliki unsur toxic berlebihan bagi tanaman. Apabila akan dilakukan revegetasi maka dibutuhkan proses yang lebih intensif dengan menambahkan pupuk NTP atau bahan penunjang lainnya.

\subsection{Hasil Survey Masyarakat \\ 3.5.1 Data Masyarakat}

Tabel 2. Responden Berdasarkan Usia

\begin{tabular}{llcc}
\hline No & Kategori & $\begin{array}{c}\text { Jumlah } \\
\text { Jiwa }\end{array}$ & Presentase \\
\hline 1. & $\begin{array}{l}\text { Anak- } \\
\text { Anak } \\
\text { 0-15th }\end{array}$ & - & $0 \%$ \\
& & & \\
\hline 2. & Dewasa & 28 & $56 \%$ \\
& 16-29 & & \\
\hline 3. & $\begin{array}{l}\text { Lanjut } \\
\text { usia }\end{array}$ & 32 & $44 \%$ \\
& 30< & & \\
\hline & Jumlah & $\mathbf{6 0}$ jiwa \\
\hline & Sumber: Data primer (2020)
\end{tabular}

Tabel 3. Responden Berdasarkan Pendidikan

\begin{tabular}{llcc}
\hline No & Kategori & $\begin{array}{l}\text { Jumlah } \\
\text { Jiwa }\end{array}$ & Presentase \\
\hline 1. & SD & - & $0 \%$ \\
\hline 2. & SLTP & 10 & $16,7 \%$ \\
\hline 3. & SLTA & 48 & $80 \%$ \\
\hline 4. & D1/2/3/S1/2 & 2 & $3 \%$ \\
\hline & Jumlah & $\begin{array}{c}\mathbf{6 0} \\
\text { Jiwa }\end{array}$ & $\mathbf{1 0 0 \%}$ \\
\end{tabular}

Sumber: Data Primer (2020)

Tabel 4. Responden Berdasarkan Pekerjaan

\begin{tabular}{llll}
\hline No & Kategori & $\begin{array}{l}\text { Jumlah } \\
\text { Jiwa }\end{array}$ & Presentase \\
\hline 1. & Petani & 20 & $33 \%$ \\
\hline 2. & Operator & 2 & $3 \%$ \\
\hline 3. & Supir & 30 & $50 \%$ \\
\hline 4. & Lain-lain & 8 & $13 \%$ \\
\hline & Jumlah & $\mathbf{6 0}$ & $\mathbf{1 0 0 \%}$ \\
\hline
\end{tabular}

Sumber: Data Primer (2020)

\subsubsection{Respon Masyarakat}

Tabel 5. Respon Masyarakat Terhadap Pertambangan dan Reklamasi Ekowisata 


\begin{tabular}{|c|c|c|c|}
\hline \multirow[b]{2}{*}{ No } & \multirow[b]{2}{*}{ Pertanyaan } & \multicolumn{2}{|c|}{ Respon } \\
\hline & & Ya & Tidak \\
\hline 1. & $\begin{array}{l}\text { Apakah masyarakat } \\
\text { mengetahui adanya } \\
\text { aktifitas } \\
\text { pertambangan? }\end{array}$ & $85 \%$ & $15 \%$ \\
\hline 2. & $\begin{array}{l}\text { Apakah masyarakat } \\
\text { mengetahui tentang } \\
\text { reklamasi? }\end{array}$ & $85 \%$ & $15 \%$ \\
\hline 3. & $\begin{array}{lr}\text { Apakah masyarakat } \\
\text { pernah mengetahui } \\
\text { lahan reklamasi } \\
\text { bekas tambang? }\end{array}$ & $39.9 \%$ & $66,1 \%$ \\
\hline 4. & $\begin{array}{l}\text { Apakah kalian } \\
\text { bersedia } \\
\text { mengembalikan } \\
\text { keseimbangan } \\
\text { ekosistem? }\end{array}$ & $73 \%$ & $27 \%$ \\
\hline 5. & $\begin{array}{l}\text { Bentuk reklamasi } \\
\text { apa yang masyarakat } \\
\text { inginkan? }\end{array}$ & $\begin{array}{l}69,5 \% \\
\text { (Ekowisat } \\
\text { a) }\end{array}$ & $\begin{array}{l}30,5 \% \\
\text { (Geowis } \\
\text { ata) }\end{array}$ \\
\hline
\end{tabular}

Sumber: Data Primer (2020)

Tabel 6. Respon Kesadaran Masyarakat

\begin{tabular}{lllllll}
\hline & & \multicolumn{5}{c}{ Respon } \\
\cline { 3 - 7 } $\mathbf{N}$ & $\begin{array}{l}\text { Pertanya } \\
\text { an }\end{array}$ & $\mathbf{1}$ & $\mathbf{2}$ & $\mathbf{3}$ & $\mathbf{4}$ & $\mathbf{5}$ \\
\hline $\mathbf{1 .}$ & $\begin{array}{l}\text { Dampak } \\
\text { negative } \\
\text { pertambang } \\
\text { an bagi } \\
\text { lingkungan }\end{array}$ & 0 & $0 \%$ & $13,6 \%$ & $35,6 \%$ & $50,8 \%$ \\
& & & & & \\
\end{tabular}

\begin{tabular}{lllllll}
\hline 2. & Dampak & 0 & 3,4 & 32,6 & $20,7 \%$ & $43,1 \%$ \\
positif dari & $\%$ & $\%$ & $\%$ & & \\
reklamasi & & & & &
\end{tabular}

\begin{tabular}{lllllll}
\hline 3. & Seberapa & 0 & $0 \%$ & $11,7 \%$ & $21,7 \%$ & $66,7 \%$ \\
besar minat & $\%$ & & & & \\
kalian untuk & & & & & \\
mewujudka & & & & & \\
n reklamasi & & & & & \\
\hline
\end{tabular}

Sumber: Data Primer (2020)

Keterangan:

$1=$ Tidak banyak

2= Lumayan Banyak

$$
\begin{aligned}
& \text { 3= Banyak } \\
& \text { 4= Banyak Sangat } \\
& \text { 5= Banyak Sangat Sekali }
\end{aligned}
$$

\subsection{Kerjasama Masyarakat}

Proses reklamasi akan terwujud dengan adanya kerjasama antar warga. Reklamasi yang akan dilaksanakan menjadi ekowisata, akan menghasilkan pendapatan tambahan bagi warga sekitar yang tidak lagi memiliki pekerjaan. Sudah banyak perusahaan pertambangan yang ada di Indonesia namun masih dapat dihitung dengan jari yang melaksanakan reklamasi secara benar dan berkelanjutan. Sisanya hanya dibiarkan atau direklamasi namun tidak seutuhnya. Dengan kata lain, reklamasi yang tidak dirawat secara kontinyu akan membuang buang uang secara percuma karena tidak ada kelanjutan dari perawatan lahan tersebut. Daripada lahan menjadi terbengkalai, akan lebih baik apabila dikembalikan kepada masyarakat untuk diolah kembali guna mengembalikan keseimbangan ekosistem dan menambah pendapatan warga setempat.

\section{IV.SIMPULAN}

Dengan menggunakan metode penelitian observasi lahan dan survey masyarakat, menghasilkan bahwa pendapat dan respon yang positif terhadap lahan yang digunakan untuk pertambangan. Sebagian masyarakat menginginkan adanya reklamasi dan dibuka ekowisata guna menghasilkan pendapat bagi masyarakat sekitar. Selain itu, mereka juga sependapat bahwa adanya ekosistem akan membuat ekosistem yang semua menjadi rusak akan menjadi hijau kembali dan juga mengurangi potensi longsor dan debu kurang sehat.

\section{REFERENSI}

Adi, A.N.I.Y.W,Widodo.S, Nurwaskito,A. 2017.Analisis Reklamasi Tambang Batukapir di Kecamatan Bunhoro 
Kabupaten Tangkep Provinsi Sulawesi Selatan. Jurnal Geomine. 5 (2), 68-75.

Afifah, N.W. 2018. Dampak Negatif Industri PT. Semen Indonesia Terhadap Masyarakat Desa Temandang. Jurnal Paradigma. 2 (1), 1-7.

Afrizal, R. Nusanto, G. Tommy, M. 2018. Rencana Teknik Reklamasi Pada Lahan Bekas Tambang Block VI PT. Semen Indonesia (Persero) Tbk. Pabrik Tuban Jawa Timur. Jurnal Teknik Pertambangan UPN Veteran. 2341-5662, 1-10.

Alkad,E. Kasim, T, Yunasril. 2017. Perencanaan Dan Biaya Reklamasi Lahan Bekas Tambang Area Tambang Batubara PT. Baturona Adimulya Desa Supat Barat Kecamatan Babat Supat Kabupaten Musi Banyuasin. Jurnal Bina Tambang. 3 (3) ,1262-1273.

Fauzi, H. 2016. Perencanaan Pembangunan Hutan Pada Lahan Bekas Tambng Batubara Berbasis Strategi Kehutanan Sosial. Jurnal Hutan Tropis Borneo. 8 (20), 33-45.

Hirfan, 2016. Strategi Reklamasi Lahan Pasca Tambang. Jurnal Ilmiah Ilmu-Ilmu Teknik. 1 (1), 101-108.

Iskandar, Suwardi, Suryaningtyas, D.T. 2018. Reklamasi Lahan-Lahan Bekas Tambang: Beberapa Permaslahan Terkait Sifat-Sifat Tanah dan Solusinya, 1-8.

Kusumawati,H. 2020. Pabrik Semen Indonesia Tuban 1994-2013. E-Journal Pendidikan Sejarah. 8 (1) , 1-9.

Pudjiharta,A. Santoso, E. 2007. Reklamasi Laham Terdegradasi Dengan Revegetasi Pada Bekas Tambang Bahan Baku Semen. Jurnal Pendidikan Hutan dan Konservasi Alam. 4 (3), 223-236.

Santosa,S. Umar,R.W， Bakri,R.M. 2020. Karakteristik Kimia-Fisika Tanah Bekas Tambang Semen Yang Ditambahn Sekam Padi Atau Serbuk Gergaji dan
Pertumbuhan Woedyetia bifurcate A.K Irvine. Serambi Engineering. 5 (4), 13381344.

Setiawam, I,B. Bahri, S. 2017. Respon Masyarakat Terhadap Pembangunan Jalan Kereta Api Di Desa Bagan Sinembah Kota Kecamatan Bagan Sinembah Kabupaten Rokan Hilir. JOM FISIP. 4 (2), 1-15

Sinting,M. 2017. Pemanfaatan Lahan Bekas Tambang Untuk Tempat Rekreaso Dengan Reklamasi Di Sungai Bingai Kecamatan Binjai Selatan Kodya Binjai. Jurnal Geografi. 3 (2), 11-17.

Sururi, A. 2018. Inovasi Kebijakan Partisipasi Publik Dalam Pengelolaan Dan Pengembangan Pariwisata (Studi Pada Kawasan Ekowisata Situterate Desa Situterate Kecamatan Cikande Kabupaten Serang). Jurnal Administrative Reform. 6 (3), 110-120.

Utami,H. 2017. Pengembangan Potensi Ekowisata Desa Malasari, Kecanatan Nanggung Kabupaten Bogor. Journal Of Tourism Destination and Attraction. 5 (1), 3-9.

Wasis,B. Sa'diah,H,S. 2019. Pertumbuhan Semai Sengon (Paraserianthes falcataria (L.) Nielsem) Pada Media Tanah Bekas Tambang Kapur Dengan Penambahan Pupuk Kompos Dan NPK. Jurnal Silvikultur Tropika. 9 (1), 51-57. 